\title{
MANAUS IMAGINADA: A CIDADE SOB A PERSPECTIVA DO IMIGRANTE HAITIANO
}

Marcus Vinícius Ferreira Gomes

Faculdade FUCAPI

mvncgomes@gmail.com

Maria Evany do Nascimento

Universidade do Estado do Amazonas

nasci.eva@gmail.com

Resumo: O presente artigo apresenta os resultados obtidos a partir do projeto de iniciação científica "Manaus Imaginada: A construção da cidade pelo olhar do imigrante haitiano", realizada entre os anos de 2014 e 2015. A pesquisa teve como objetivo analisar aspectos do imáginário urbano construído por imigrantes haitianos que vivem na cidade de Manaus. Os Imaginários Urbanos (SILVA, 2001) são percepções construídas pelos cidadãos. Percepções que não são meras idealizações, mas são materializadas no espaço e na forma de ser e viver a cidade, dando um ritmo, uma identidade própria a cada lugar. Por sua vez, o Design Urbano (NASCIMENTO, 2014), baseado numa estrutura interdisciplinar, metodológica e interessado nos aspectos simbólicos e funcionais do espaço, surge como uma metodologia de estudo da cidade, pois fornece meios de compreender a cidade vivida por seus cidadãos. Quanto à sua natureza, a pesquisa é qualitativa, tendo como procedimento de coleta de dados a aplicação de entrevistas semiestruturadas que foram analisadas seguindo metodologia de Nascimento (2014) fundamentada em Quentin Skinner e na história das ideias. Tendo como objeto de estudo a percepção da cidade a partir de estrangeiros, a entrevista foi desenvolvida a partir dos estudos de memória social (BOSI, 1994), imigração haitiana (FERNANDES et al, 2014) e imaginários urbanos (SILVA, 2011). Na percepção dos entrevistados a praia da Ponta Negra foi escolhida como imagem-símbolo da cidade e a apontam como espaço de relaxamento e divertimento. $\mathrm{O}$ convívio social interferiu diretamente na relação dos imigrantes com a cidade, sendo unanimidade a afinidade com os cidadãos manauaras, sendo o principal determinante para a permanência.

Palavras-chave: Design Urbano; Imaginários Urbanos; Tradução Cultural

Abstract: This article presents the results obtained from the research project "Manaus Imagined: The construction of the city through the eyes of the Haitian immigrant" held between the years 2014 and 2015. The research aimed to analyze aspects of the urban imaginaries built by Haitians immigrants living in Manaus. The Urban Imaginary (SILVA, 2001) is perceptions that are not mere idealizations but are materialized in space 
and the way of being and living the city, giving a rhythm, its own identity to each place. In other hand, the Urban Design (NASCIMENTO, 2014), based on an interdisciplinary structure, methodology and interested in the symbolic and functional aspects of space, emerges as a city of study methodology, it provides a means of understanding the city experienced by citizens. As to its nature, the research is qualitative, with the data collection application of semi-structured interviews were analyzed following Nascimento (2014) methodology based on Quentin Skinner and the History of ideas. As an object of study the perception of city from foreigners, the interview was developed from the social memory studies (BOSI, 1994), Haitian immigration (FERNANDES et al, 2014) and urban imaginary (SILVA, 2011). Interviewees perceived the beach of Ponta Negra was chosen as a city-symbol and point to relaxation and fun space. The social life interfered directly in the relationship of immigrants to the city, being unanimously affinity with manauaras citizens, being the main determinant for the stay.

Keywords: Urban Design; Urban Imaginaries; Cultural Translation

\section{INTRODUÇÃO}

A cidade de Manaus serviu como passagem temporária para imigrantes haitianos que estão em trânsito, rumo ao sul e ao sudeste do país. O intenso fluxo de entrada e permanência de imigrantes mobilizou a sociedade civil a encontrar soluções para acolher os imigrantes na cidade, houve diversas mobilizações e iniciativas como abrigos e redes de solidariedade com o intuito de auxiliar a recepção e adaptação dos haitianos na cidade. Uma das principais iniciativas em Manaus foi organizada pela Pastoral do Migrante, instituição ligada à Paróquia de São Geraldo, liderada pelos Padres Valdeci Molinari e Geomino Costa, que acolheram e proveram as necessidades básicas de mais de seis mil haitianos, segundo informações da pastoral. A chegada dos imigrantes haitianos à Manaus trouxe um olhar diferenciado para o cotidiano manauara, sendo o contigente imigratório em caráter humanitário mais representativo entre os anos de 2010 e 2014 conforme o gráfico abaixo:

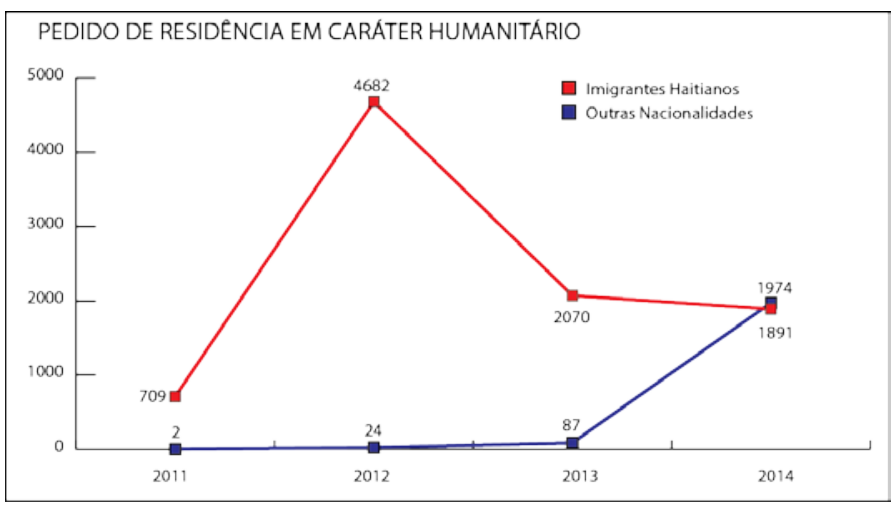

Gráfico 1. Quantitativo dos Vistos humanitários. Adaptado de CNIg, 2014.

A presente pesquisa está baseada numa abordagem interdisciplinar de análise e interpretação da percepção de imigrantes sobre a cidade, com o objetivo de traduzir, 
por meio do design, os aspectos simbólicos e funcionais do espaço urbano captada por imigrantes haitianos na cidade de Manaus. Para o desenvolvimento da pesquisa será operacionalizado os conceitos de Imaginários Urbanos (SILVA, 2001) e Design Urbano (NASCIMENTO, 2014). Os imaginários urbanos são percepções inconscientes construídas a partir da vivência na cidade, que são "materializados" através de simbolismos, discursos e comportamentos, causando efeitos na "cidade real". Sendo assim, passaremos a abordar a cidade a partir de três perspectivas: $A$ cidade vista, $A$ cidade marcada e A cidade imaginada.

Segundo Silva (2001) a cidade vista é revelada pelas imagens e representações que o cidadão evoca do espaço urbano, que ao viver a cidade, é visualmente impressionado por campanhas publicitárias, graffitis, monumentos, pessoas e outros elementos urbanos, criando dessa forma o ponto de vista cidadão, quando somado a outros "pontos de vistas" projeta a percepção de um grupo social sobre a cidade. A cidade marcada é delimitada por seus territórios e os usos atribuídos aos seus espaços, que revelam quais são os lugares para morar, para trabalhar, para diversão, para relaxar, entre outros usos. Desvelando as preferências e as segmentações feitas na cidade, pelos cidadãos. A cidade imaginada é um objeto simbólico "construído em um nivel superior de percepção" (inconsciente), formada pelo conjunto de construções sociais e espaciais que se materializam nas expressões cidadãs, determinando a forma como o cidadão responde ao espaço urbano.

Em síntese, o estudo da percepção imaginária de uma cidade, além de considerar os aspectos físicos e sociais, também interpreta os símbolos e evocações utilizadas para representá-la. Portanto, a estrutura interdisciplinar do design orientado por uma metodologia para o estudo do espaço surge como alternativa para a interpretação dos aspectos simbólicos e funcionais do espaço urbano. Tendo como objetivo a compreensão do espaço, do cidadão e das suas relações.

\section{METODOLOGIA}

Para a construção da metodologia, foi realizado um estudo exploratório através da pesquisa bibliográfica baseada nas categorias: migração, cidade, design e metodologia de pesquisa. Na pesquisa inicial foram prospectados dez publicações eletrônicas (Coletânea de artigos, revistas, livros e manuais digitais), trinta e quatro artigos, uma monografia, duas dissertações, três teses e vinte e um livros. Para a realização da pesquisa documental as seguintes palavras-chaves foram definidas: imigração haitiana e cidade. Ao total foram prospectados dezessete matérias de jornais eletrônicos, uma resenha de imprensa, cinco relatórios científicos e três documentos oficiais do governo federal brasileiro. Todas as pesquisas foram realizadas em bancos de dados online (Scielo e Google) em português, espanhol e inglês.

O critério para a filtragem do material foi definido pela adequação ao recorte específico da pesquisa. Sendo assim, chegou-se a seguinte configuração: quatro livros, dois relatórios científicos, duas teses de doutorado e um artigo, além do material coletado na pesquisa documental. O resultado da pesquisa bibliográfica e documental gerou seis fichas de leitura e um artigo sobre o referencial teórico.

A construção do instrumental de pesquisa foi dividida em seis blocos de perguntas interdependentes, podendo ser analisados individualmente ou em conjunto: Identificação; Memória e interação; Tempo e memória; Os espaços da memória; 
Memória e política e Memória e trabalho. As categorias de análise foram fundamentadas no estudo realizado sobre a imigração haitiana disponibilizado pelo Ministério do Trabalho e Emprego (FERNANDES ET AL. 2014), e nas obras Memória e Sociedade: lembranças de velhos (BOSI, 1994) e Imaginários Urbanos (SILVA, 2001).

A coleta de dados foi realizada por meio da aplicação de entrevista semiestruturada a imigrantes haitianos que foram auxiliados pela Casa de Apoio ao Migrante, entidade ligada à Paróquia de São Geraldo, em Manaus. O público-alvo foi definido por imigrantes acima de 18 anos que optaram por estabelecer residência permanente em Manaus e que já estavam integrados à sociedade manauara há mais de um ano. Segundo Gil (1989) a entrevista é uma das técnicas mais utilizadas no âmbito das ciências sociais, pois permite não apenas a "coleta de dados, mas o diagnóstico e orientação".

Foi aplicada uma entrevista teste para avaliar a percepção da cidade por imigrantes. $O$ entrevistado foi um imigrante nigeriano que vive na cidade há sete anos, tempo suficiente para a integração à sociedade local. A entrevista foi realizada em dois momentos distintos com aproximadamente 30 e 20 minutos de duração respectivamente. Após a entrevista foi realizada as etapas de transcrição e análise, alcançando um resultado satisfatório. A análise em conjunto dos seis blocos de perguntas contribuíram para a interpretação detalhada da percepção do entrevistado sobre a cidade. Entretanto, foi possível notar que as informações contidas no bloco "Os espaços da memória", foram suficientes para captar as informações relevantes para a pesquisa. Sendo assim, foi realizado o recorte para os blocos: "Identificação" e "Os espaços da memória": tendo como objetivo, respectivamente, coletar as informações de identificação para traçar o perfil demográfico e captar a percepção da cidade a partir da vivência no espaço público, através dos usos e funções atribuídas pelo entrevistado. Durante o processo de transcrição e análise foi necessário considerar o esforço do entrevistado em traduzir para uma língua estrangeira suas impressões e percepções.

A análise de dados foi fundamentada na análise do discurso, seguindo metodologia de Nascimento (2014) que tem como base o contextualismo linguístico de Quentin Skinner e na história das ideias. O método consistiu na análise do vocabulário utilizado pelo entrevistado para descrever suas percepções e impressões a fim de identificar seus "motivos" e "intenções". Buscou-se destacar as palavras e/ou expressões mais comuns, para a formação do "vocabulário normativo" para a definição das categorias de análise.

Contudo, a presente pesquisa não pretende ser um registro demográfico, estatístico ou de amostragem, o objetivo é registrar e analisar aspectos do imaginário da cidade de Manaus através da percepção de imigrantes haitianos ou parafraseando Bosi (1994) "o objetivo é colher memórias de imigrantes", valorizando a experiência individual num contexto social.

\section{REFERENCIAL TEÓRICO}

O Design Urbano, originado na intersecção entre arquitetura e planejamento urbano, surgiu na revolução urbana na década de 1960 na qual a cidade passava por um acelerado processo de desenvolvimento, no qual os aspectos construtivos tinham 
maior relevância que os aspectos simbólicos, funcionais e sociais. Nesse contexto o Design Urbano surge como um "espaço comum" entre projetistas e planejadores, com o intuito de desenhar a cidade orientada aos seus cidadãos visando compreender os espaços públicos como um projeto, pois atende a uma finalidade, a um público e a uma intencionalidade.

Portanto, passaremos a abordar o Design Urbano da seguinte maneira:

"É interessante pensar hoje essas possibilidades para as quais se abre o
Design Urbano, como um plano de atuação que por sua estrutura
interdisciplinar e preocupação com o projeto e com o aspecto simbólico e
funcional da cidade se mostra viável para a cidade contemporânea."
(NASCIMENTO, 2014; pág. 138)

A estrutura interdisciplinar do design permite o diálogo e a interação com outras áreas do conhecimento que possuem o espaço urbano como seu objeto de estudo: arquitetura, engenharias, sociologia, antropologia e etc. A metodologia projetual valida o processo de design e permite a reprodução. $O$ aspecto simbólico $e$ funcional é levado em consideração, por ser o cidadão o alvo de todo projeto em Design Urbano. O designer pode atuar como intérprete da cidade que é vivenciada pelos cidadãos que diariamente estão expostos aos códigos e signos que constituem o espaço urbano. A percepção dessas informações irá contribuir para a forma como esses cidadãos vivem e entendem sua cidade.

A cidade não pode ser compreendida, de forma fragmentada pelas óticas econômica, sociológica ou estrutural, pois sua essência está na resultante desses vetores, sendo definida por Argan (1989) como um complexo sistema de informações. $\mathrm{O}$ designer pode ser o intérprete desse sistema de informações, gerenciando e ordenando o espaço através de produtos, serviços ou processos. Nascimento (2014) compreende o design urbano como "gerenciador da construção de valores na cidade contemporânea, agregando elementos culturais, e os diversos profissionais que contribuem para isso" através do diálogo livre e aberto com outras áreas do conhecimento como: Arquitetura, Urbanismo, Sociologia, Antropologia, Artes e etc.

Para que o "Projeto Urbano" possa atender ao público desejado, é necessário, entre outros fatores, compreender seu modo de vida, suas aspirações, seus valores, identificar locais e reconhecer suas funcionalidades. Nesse sentido, o estudo dos Imaginários Urbanos contribui para esse objetivo. Segundo Silva (2001) a cidade é construída a partir da imagem que os seus cidadãos formam através das suas relações com a urbe. Nesse aspecto Silva (2001) endossa o discursso de Argan (1989) que atribui ao cidadão a participação na construção da cidade:

\footnotetext{
“Devemos, portanto, levar em conta, não o valor em si, mas a atribuição de valor, não importa quem a faça e a que título seja feita. De fato, o valor de uma cidade é o que lhe é atribuído por toda a comunidade."

(ARGAN, 1989; pág. 228)
}

Além da atribuição de valor gerado pelos seus habitantes, Argan (1989) concebe a cidade como um objeto coletivo que é construído através das interações dos cidadãos com a cidade, atribuindo valor aos espaços, enquanto Nascimento (2014) reafirma atribuindo ao Design Urbano o papel de "gerenciador da construção de valores na cidade contemporânea". 
Para Silva (2011) a imagem da cidade é construída "lenta e coletivamente", à medida que seus habitantes vivenciam o cotidiano, através da relação social, espacial e representativa. É importante o estudo do espaço físico da cidade, como defende Lynch (1997) por seu aspecto visual, por suas ruas, construções e pelo seu "desenho", assim como é importante o estudo social como defende Simmel (1903), através das relações humanas e culturais nas grandes cidades, mas há uma relação "que não é apenas física ou social, mas representativa": o estudo do espaço imaginário, onde "o físico produz efeitos no simbólico". Segundo Silva (2011) para compreendermos a relação imaginária dos cidadãos com sua cidade, é necessário entender os aspectos físicos naturais, os construídos, os usos sociais e as modalidades de expressão.

O estudo dos aspectos físicos naturais e construídos da cidade compreende o estudo da forma ou desenho da cidade, a disposição e localização dos bairros, os meios de locomoção, o mapeamento dos espaços utilizados para a compreensão dos usos sociais e as impressões causadas pelo viver a cidade. As modalidades de expressão são percepções "materializadas" no espaço físico que podem ser o graffiti, intervenções artísticas, discursos e outros meios expressivos.

Entendendo a cidade como um complexo sistema de informação, ao vivê-la, o cidadão se depara com sistemas de sinalização, de comunicação, construções, monumentos referenciais e outros cidadãos que são parte integrante desse sistema, que impressionam e são impressionados, nesse sistema nada está estático, o "ser urbano" está sempre em construção. Essa interação dá ao espaço a habilidade de comunicar-se ou de revelar-se. Argan (1989) acredita que essa interação dá ao cidadão a "possibilidade de reagir ativamente ao ambiente", interpretando e dando novos significados aos percursos, às construções e aos espaços de convivência. O imaginário de uma cidade é mutável e sofre alterações num contínuo processo de construção e desconstrução, afinal, quando os cidadãos mudam a cidade muda e acompanha esse ritmo de transformação. A cidade é formada e transformada a partir da vida cotidiana, no contato com o "outro". "Uma cidade se autodefine por seus próprios cidadãos, seus vizinhos e seus visitantes." (SILVA, 2011; pág. XXV), pode-se perceber a dinâmica horizontal das relações humanas na cidade que a partir do cotidiano a parte revela o todo.

Ao viver a cidade e percorrer o seu espaço, o cidadão está exposto a uma infinidade de sensações, impressões e oportunidades. Segundo Bosi (1994) a vivência nos lugares formam um elo emocional que funciona como um mapa afetivo da memória, as significações dadas aos espaços são definidas pelas funções atribuídas a eles. Pode-se analisar a significação do espaço, como parte do imaginário urbano. Estudar os Imaginários é interpretar percepções construídas pelos cidadãos que vivem numa mesma cidade. Percepções que não são idealizações, mas materializações no espaço e na forma de ser e viver a cidade, dando um ritmo, uma identidade própria a cada lugar.

\section{ANÁLISE DE DADOS}

Foram entrevistados três imigrantes do sexo masculino, os nomes utilizados não são os verdadeiros para preservar a identidade dos entrevistados: Oliver, é casado apenas no religioso com uma haitiana, é mestre de obras. Pierre é solteiro, sendo formado em mecânica industrial é gerente de uma fábrica do ramo alimentício e Louis 
é casado, foi motorista no Haiti e atualmente é ajudante de pedreiro. A análise está dividida em dois eixos semânticos: Imagem de Percurso, na qual abordaremos o caminho percorrido para chegar à Manaus e Imagem de Permanência, no qual serão abordadas as percepções construídas a partir das vivências na cidade.

\title{
4.1 Imagem de percurso
}

Como abordado no referencial teórico, a decisão por emigrar é construída coletivamente, na qual um membro da família é o responsável pelo sustento e manutenção dos familiares que ficaram. Oliver saiu do Haiti e foi para o Panamá, Peru e entrou no Brasil pela fronteira de Tabatinga e depois seguiu para Manaus. Pierre morava legalmente no Equador, mas ao saber que o Brasil tinha permitido o visto de asilo humanitário para haitianos, decidiu emigrar para o Brasil a fim de melhores condições de vida. Passou por Peru e entrou no Brasil também pela fronteira de Tabatinga e seguiu para Manaus. Louis foi mais direto e informou apenas que entrou no Brasil pela fronteira no Acre e seguiu para Manaus.

\subsection{Imagem de permanência}

\author{
"Porque são muitas imagem que representa e todas são \\ bonitinhas...aí não pode escolher uma porque é que vem..." (Oliver) \\ “...eu posso falar que Manaus é uma cidade de oportunidade para a \\ pessoa crescer na vida." (Pierre) \\ "Muita praia, mas aqui eu não vi mar, mas no Haiti tem muito mar."
}

(Louis)

Na seção imagem de permanência foram analisadas as percepções da cidade, que revelam os mapas afetivos construídos a partir da vivência nos espaços públicos e privados. As categorias de análises foram extraídas com base na análise do discurso dos entrevistados, sendo elas: Imagem do País, Imagem da Cidade e Imagem das Pessoas.

\subsubsection{Imagem do País}

\author{
"Eu morei minha vida foi viajando todo o tempo, eu nunca acho um \\ país que trata melhor que aqui... Brasil é ótimo." (Oliver) \\ “Porque a ideia é porque antigamente (..) eu não tinha a vontade \\ hoje pelo Brasil, quando eu sair lá do meu país depois do terremoto eu tive \\ a ideia, a ideia é pegar um país que falar de seu cultura, sua língua, a \\ cultura para conseguir ficar, eu pensei que seria Guiana Francesa, mas eu já \\ tá aqui, olha as pessoas ficou um tempinho conseguir um emprego na \\ época, eu gostar e fiquei." (Pierre)
}

Conforme abordado anteriormente, o Brasil não fazia parte da rota migratória haitiana. Com o incentivo do governo federal muitos haitianos viram no Brasil uma nova oportunidade. Pierre nunca tinha pensado em vir para o Brasil, pois planejava ir para a Guiana Francesa, mas ao conviver em Manaus e conquistar um emprego, decidiu por permanecer na cidade. $O$ interessante é que o entrevistado destacou que primeiro observou as pessoas, permaneceu um tempo e depois conseguiu um emprego. Pode-se perceber que as relações sociais tiveram importância na decisão por permanecer. 


\subsubsection{Imagem da Cidade}

“É normal, a gente vive, trabalha (...) Cidade Nova." (Pierre)

"Vários... Presidente Figueiredo, Ponta Negra, o shopping é esses lugar." (Pierre)

"Ah, Ponta Negra eu posso falar é um point, tipo um cartão postal da cidade (...) um monte de pessoas que tem... Sei lá! Ponta Negra pode ser." (Pierre)

"O mais, a verdade é o shopping, que eu falei, a Cachoeirinha, muito tipo, como diz (...) 3, 4 vez por ano, mas o shopping eu ia quase todo final de semana." (Pierre)

“É... (...) Manaus é uma cidade bonita, maravilhosa e para mim quente, quase o mesmo clima do nosso país..." (Pierre)

Entre os três entrevistados, Pierre está há mais tempo na cidade e demonstrou estar mais adaptado. Indicou o convívio social e a conquista do emprego como a motivação para permanecer na cidade. Apontou o shopping, a praia da Ponta Negra e um bairro da zona sul como lugares para diversão e escolheu um bairro da zona norte para morar. Citou a beleza da cidade e a similaridade do clima com o de sua terra natal. Um ponto interessante a observar é que a adaptação do entrevistado à cidade faz com que os espaços para diversão estejam além da própria cidade. Ele indica a cidade de Presidente Figueiredo como alternativa de diversão e relaxamento.

O estudo do imaginário da cidade também inclui o estudo da percepção do território. Para Silva (2001) a noção de território é construída coletivamente à medida que se vai vivendo os espaços. Assim como o urbano, o território é algo dinâmico e vai "territorializando-se na medida em que estreita os seus limites". Dessa forma, aquele que não está habituado ao espaço, ou à forma de uso, ou seja, aquele que não pertence a um território específico, não se adapta e é denunciado como "estrangeiro". Pode-se perceber o quanto Pierre está adaptado ao convívio social e ao uso dos espaços, pois passa a construir por si mesmo os caminhos e percursos na cidade e além dela.

"Decidi porque aqui foi que eu gosto. Os outros... as outras cidade tem tempo que és muito frio e que eu não aguento o frio, aqui em Manaus tá sempre quente, que chove e fica quente..." (Oliver)

"A vida aqui, a gente tá vivendo bem, não sei pra outro, mas eu tô muito." (Oliver)

"Depois que a gente entra aqui, morou no São Jorge, mas não me adaptei porque era muita droga no São Jorge eu saí e entro aqui pro bairro Presidente Vargas, a gente tá pra três anos lá e não tá pensando em mudar não." (Oliver)

"Só as vezes saio para a Ponta Negra, eu não gosto porque.... eu sou uma pessoa que não tá gostando muito de... de coisa assim não, porque as vezes eu não gosto de ir pra festa... a gente não gosta de coisa assim..." (Oliver)

"É... há muitos lugares bonitos que dá pra representar." (Oliver) 
“Primeira imagem... primeira imagem...? Porque são muitas imagem que representa e todas são bonitinhas...aí não pode escolher porque é que vem..." (Oliver)

“É muito bonito. Como foi aí no Arena da Amazônia, lá na Ponta Negra, tem outro onde é que tá todo (incompreensível) é aí que você chega lá e se (incompreensível)... dá pra representar muita coisa bonita. E não pode escolher uma só." (Oliver)

“O primeiro lugar que eu gostei muito quando da casa que a gente chegou, só eu que a Presidente Vargas que é muito tranquilo pra mim, a gente entra qualquer hora diz que tem violência, mas nunca aconteceu nada comigo." (Oliver)

Oliver ao ser questionado sobre o que o motivara a permanecer em Manaus, disse que ficou porque gostou da cidade e se adaptou ao clima, indicando que a cidade está sempre quente, enquanto as outras pelas quais passou não se adaptou por conta do clima frio. Morou inicialmente num bairro na zona oeste da cidade e sua percepção foi de insegurança, pois não se adaptou por conta da intensa circulação de narcóticos. Mudou-se e está morando há três anos no centro da cidade, em sua percepção a região é mais tranquila e segura. Ao ser questionado sobre os lugares que utiliza para diversão e relaxamento, disse que não gosta de ir a festas e não demonstrou uma vida social ativa, mas destacou que esporadicamente gosta de ir à Ponta Negra. Ao ser questionado sobre os símbolos que representam a cidade o entrevistado não soube inicialmente definir e afirmou que há muitos lugares que podem representar e que não se pode escolher um. Após refletir, indicou a Arena da Amazônia e a Ponta Negra como lugares que representam a cidade de Manaus a partir de sua percepção.

Retomando ao referencial teórico, Argan (1989) destaca: "Devemos, portanto, levar em conta, não o valor em si, mas a atribuição de valor, não importa quem a faça e a que título seja feita". O valor atribuído pelo cidadão aos espaços determina a forma como ele se relacionará com ele e a função que esse espaço terá. A Arena da Amazônia é próxima à Paróquia de São Geraldo, como uma construção recente e imponente ela possui a função de marco referencial no espaço da cidade. O valor atribuído por Oliver à Arena da Amazônia como símbolo representante da cidade pode indicar um olhar otimista para o futuro, para as possiblidades do que a cidade pode se tornar. Ao indicar apenas a Ponta Negra como lugar de divertimento e relaxamento e deixar claro que ele e a esposa "não gostam de coisa assim", é possível perceber que mesmo vivendo na cidade há pelo menos três anos, sua relação com ela ainda é limitada.

"É foi muito bem para mim, eu gosto da temperatura aqui e... eu quero ficar aqui mesmo!" (Louis)

“Ah, tá! Para mim foi, eu fui trabalhar todo dia... graças a Deus... eu fui bem." (Louis)

"Se eu gosta de morar aqui, então? Sim, eu gosto." (Louis)

"Ah... diversão? Só em casa." (Louis)

“Ah não... eu não tá... eu não sabe Manaus bem não... Porque eu só saí pra trabalhar, então fico bem em casa, não passear muito não. Por isso eu não saio muita coisa aqui em Manaus." (Louis)

"Só eu saber lá em Ponta Negra, eu gosto de lá. Ponta Negra muito bacana lá. Entendeu? Eu fui lá tomar banho, depois... as vezes eu fui lá no centro só isso, aí não sabe muito lugar não. E... Eu gosta a praia... a praia 
tem muita gente lá, é... tomando banho, entendeu? Eu, as vez quando chegar domingo, eu levar a minha esposa, lá tomando banho, depois voltar em casa." (Louis)

"Muita praia, mas aqui eu não vi mar, mas no Haiti tem muito mar." (Louis)

Louis está na cidade há um pouco mais de um ano, e através do seu discurso podemos perceber que sua relação com a cidade ainda é de estranhamento, quando não está trabalhando, está em casa. 0 entrevistado também indica o emprego e o clima como fatores que o motivaram a permanecer na cidade. Apesar de gostar de morar na cidade, apontou sua casa e a Ponta Negra como espaço de relaxamento e diversão.

Através de sua última frase pode-se perceber que ao olhar para a cidade, a comparação com sua terra de origem ainda é muito evidente. Segundo Bosi (1994) a memória é delimitada por marcos "onde a significação da vida se concentra", são os momentos que vivemos que constroem nossa percepção do tempo, o ato de emigrar é um importante acontecimento na vida do imigrante, que ao estar imerso em outro contexto cultural, necessita de um tempo para assimilação e adaptação. Da mesma forma como Calvino (1989) em sua obra, Cidades Invisíveis, nos apresenta o famoso viajante Marco Polo que para todas as cidades que visitava, tinha Veneza por modelo: "Para distinguir as qualidades das outras cidades, devo partir de uma primeira que permanece implícita. No meu caso, trata-se de Veneza.". O processo de adaptação e assimilação na/da cidade, implica viver os espaços, perceber o ritmo da dinâmica urbana, interagir com outros cidadãos, enfim vivendo o urbano em sua urbanidade o "estrangeiro" passará a reconhecer os códigos e símbolos, passando a construir por si mesmo sua vivência urbana.

\subsubsection{Imagem das pessoas}

"As pessoas de Manaus são muito pra mim é ótimo que ninguém me trata mal, tudo eu quase o brasileiro, quase tudo é assim, tudo sabe como trata as pessoa, pra mim não tem crítica não." (Oliver)

“... e os povo, o manauara, são um pessoal que... tipo assim, que é ajudador, (...) que você fala assim: Gente, eu (...) eu posso falar que Manaus é uma cidade de oportunidade para a pessoa crescer na vida."

(Pierre)

“... e quero agradecer você que procura imigrante, que dá ajuda quando a pessoa entra no país, precisa de outra pessoa para orientar mais, dá uma orientação talvez, é um trabalho que admiro muito." (Pierre)

E... eu gosta a praia... a praia tem muita gente lá, é... tomando banho, entendeu? (Louis)

No geral a visão dos três entrevistados sobre os manauaras é positiva. Oliver destacou o tratamento cortês dos manauaras, Pierre destacou a gentileza e a disponibilidade para ajudar e Louis destacou o convívio social no espaço público. A recepção dos imigrantes na cidade foi caracterizada por ações solidárias mobilizadas por integrantes da sociedade civil. Sakata (2011) assim como Silva (2001) acreditam que a apropriação dos espaços é definida a partir da sua utilidade. O convívio social estimulado através do espaço público "tem efeito compensatório às desigualdades de 
renda" (SAKATA, 2011; pag. 20), atribuindo ao espaço público uma personalidade democrática e integradora, pois permite a interação e o contato entre os cidadãos.

A cidade vista, a partir da perspectiva dos entrevistados, é caracterizada como "bonita", a partir da vivência nos espaços. O recorte da cidade marcada foi revelado pela unanimidade dos entrevistados aos escolherem a Ponta Negra como imagemsímbolo da cidade, eles destacam o convívio social proporcionado pela praia e a apontam como espaço de relaxamento e divertimento. Apesar do intenso processo de urbanização, a relação da cidade com o rio determina alguns comportamentos e usos no espaço urbano. Para a construção da cidade imaginária, o convívio social merece destaque, foi unanimidade entre os entrevistados a afinidade com os cidadãos manauaras e muitas vezes o fator determinante para a permanência. No tempo em que estão na cidade desenvolveram laços afetivos e fraternos considerando as relações construídas mais importantes no processo de adaptação e assimilação do novo contexto cultural. A relação com os cidadãos interferiu diretamente na relação dos imigrantes com a cidade.

Pode-se concluir que os entrevistados estão satisfeitos com a cidade e encontraram em Manaus os fatores necessários para sua adaptação e desenvolvimento, reafirmando a característica acolhedora de Manaus. Ao longo dos últimos seis anos imigrantes haitianos estão passando a compor o espaço urbano de Manaus, um processo de assimilação não só para os imigrantes, mas também por parte da cidade que os recebem e à medida que os visitantes vão se tornando novos moradores, a cidade vai recebendo novas características.

\section{CONCLUSÃO}

O presente trabalho foi proposto como análise e interpretação da percepção imaginária da cidade por parte de imigrantes haitianos em Manaus. Ao analisar o perfil de cada entrevistado foi constatada a percepção do espaço em função do tempo de permanência. Pierre está há quase cinco anos na cidade e está integrado ao convívio social e ao ritmo urbano de Manaus. Oliver está há um pouco mais de três anos, ainda está no processo de adaptação, utiliza alguns espaços da cidade, mas ainda permanece distante do ritmo citadino, já Louis está um pouco mais de um ano na cidade e ainda apresenta uma relação de estranhamento, mas a partir das relações com a cidade (através dos usos dos espaços e do convívio social) o processo de assimilação vai sendo desenvolvido. Portanto temos o registro de três imigrantes haitianos em momentos distintos: A chegada, a adaptação e a incorporação à cultura local. É importante ressaltar que todo processo de tradução é incompleto, pois "implica no reconhecimento e a identificação dos elementos/ideias e espaços intraduzíveis" (OLIVEIRA, 2013), sendo a atual pesquisa um dos recortes possíveis.

Em síntese, o Design Urbano surge como uma possibilidade de estudo da cidade, afim de compreendê-la a partir dos aspectos simbólicos e funcionais, materiais e imateriais, sociais e orgânicos. O estudo do imaginário urbano atribui à cidade a capacidade de comunicar-se afim de refletir e formar os valores e identidades dos cidadãos que a habitam. Num processo recursivo é construída pelo seus cidadãos, que em contrapartida, são construídos por ela. 


\section{REFERÊNCIAS}

ARGAN, G. História da arte como história da cidade. Tradução: Pier Luigi Cabra. 4a Ed. São Paulo: Martins Fontes, 1998. (Coleçao 2)

BOSI, E. Memória e sociedade: lembranças de velhos. 3a Ed. São Paulo: Companhia das Letras, 1994.

FERNANDES, D. et all. Estudos sobre a migração haitiana ao Brasil e diálogo bilateral. Durval Fernandes, Maria Consolação Castro, Bruna Pimenta, Vanessa Carmo, Tais Xavier e Paula Guedes. Belo Horizonte, 2014.

LYNCH, K. A imagem da cidade. São Paulo: Martins Fontes, 1997

NASCIMENTO, M. Do discurso à Cidade: políticas de patrimônio e a construção do espaço público no Centro Histórico de Manaus. Tese de Doutorado defendida no Rio de Janeiro, em 2014 - Pontifícia Universidade Católica do Rio de Janeiro - PUC-Rio. Programa de Pós-graduação em Design.

Disponível em: http://www.dbd.pucrio.br/pergamum/biblioteca/php/mostrateses.php?open=1\&arqtese=1011910_2014_I ndice.html (Acessado em 02/06/2016)

OLIVEIRA, Alexandre. Santos de. Identidade cultural e ensino do design no Amazonas. Tese de Doutorado defendida no Rio de Janeiro, em 2013 - Pontifícia Universidade Católica do Rio de Janeiro - PUC-Rio. Programa de Pós-graduação em Design.

Disponível em:

http://www2.dbd.puc-rio.br/pergamum/tesesabertas/0912508_2013_cap_4.pdf. (Acessado em 02/06/2016)

\section{RELATÓRIO SOBRE AS AUTORIZAÇÕES DE TRABALHO CONCEDIDAS PARA}

ESTRANGEIROS. Coordenação Geral de Imigração - CGIg. Ministério do Trabalho e Emprego. Brasília, 2014. Disponível em :

https://oestrangeirodotorg.files.wordpress.com/2015/03/relatc3b3rio-cgig-finalcompleto-ult-versc3a3o.pdf (Acessado em 02/06/2016)

SAKATA. Francine Gramacho. Paisagismo Urbano: Requalificação e Criação de Imagens. São Paulo. Ed.: Edusp, 2011.

SILVA, A. Imaginários Urbanos. São Paulo: Perspectiva; Bogotá: Convênio Andres Bello, 2001

SIMMEL, G. As grandes cidades e a vida do espírito (1903). Rio de Janeiro: Mana. v. 11, n 2, Outubro 2005.

Disponivel em: http://www.scielo.br/scielo.php?script=sci_arttext\&pid=S0104-

93132005000200010\&/ng=en\&nrm=iso - Acessado em 22/02/2015 